\title{
Questioning the Way That We Measure Consumers' Product Involvement Levels: How Wine Awards Exposed Differing Involvement Levels
}

\author{
Rosemarie Neuninger ${ }^{1, *}$, Damien Mather ${ }^{1}$, Tara Duncan ${ }^{2}$, Rob Aitken $^{1}$ \\ ${ }^{1}$ Department of Marketing, University of Otago, New Zealand \\ ${ }^{2}$ Department of Tourism, University of Otago, New Zealand
}

Copyright $\bigcirc 2016$ by authors, all rights reserved. Authors agree that this article remains permanently open access under the terms of the Creative Commons Attribution License 4.0 International License

\begin{abstract}
Consumer levels of product involvement have conventionally been explored using questionnaires that aim to identify the existence of different consumer segments. However, the research presented here suggests that whilst questionnaires are suited to large numbers of participants, they may not provide an accurate picture of product involvement levels. Using quantitative and qualitative research to investigate involvement levels with wine and the influence of awards on purchase decisions, this paper presents results from two different types of methods that reveal differing levels of involvement. A consumer questionnaire $(n=44)$ classified participants into high and low involvement groups. Four focus groups with these participants were then conducted. Results from the focus groups indicate that the participants' involvement levels were not equivalent to those allocated as a result of the questionnaire responses. These results suggest current marketing scales need to be adapted to better segment wine consumers according to their level of product involvement.
\end{abstract}

Keywords Involvement, Wine, Scales, Qualitative and Quantitative Research, External Validity

\section{Introduction}

Consumers' level of involvement has long been an important topic of interest in marketing research. As part of the decision-making process consumers are said to go through five stages to make choices between desirable alternatives $[1,2]$. Fundamentally, the amount of time and effort that a consumer will invest (level of involvement) to make a product choice varies widely [2]. During the decision-making process, consumers unconsciously adopt either a high or a low level of involvement according to the degree of "personal relevance with the product" [3, p. 342].
Zaichkowsky [3] found that there was a significant difference in involvement level for different products. Given the differences in consumers' choice behaviour $[4,5]$, past studies investigated different product categories including coffee, bubble bath soap, breakfast cereal, calculators, automobiles, and cell phones as well as wine $[3,4,6-8]$. However, most of these studies are based on an involvement scale that was developed over twenty years ago $[4$, p. 50] that may have lost relevance over time and thus may no longer profile the behaviour of today's modern consumer. The aim of this paper is to use quantitative and qualitative research to investigate involvement levels with wine and how the influence of wine awards interacts with involvement on purchase decisions.

\subsection{Scales That Have Been Used in the Past to Measure Consumers' Level of Product Involvement with Wine}

Past studies have used different types of scales to measure consumers' wine involvement. These scales were often formulated to measure consumers' involvement with generic products [4]. For instance, the question "I have a strong interest in _ ", was first suggested by Laurent and Kapferer $[4$, p. 50], who thought that the items of their scale should "fit any product- from bras to cars. From dishwashing liquid to champagne". Over the years, this question has also been used in other studies to measure wine involvement [5, 6, 9-11]. However, the applicability of such a question to wine is uncertain. Compared to many other food product categories the wine category typically offers more assortments (from both national and international origin) in a typical retail outlet, with the possible exception of public bars. The current wine involvement scales have been developed using numerous involvement-related concepts and there has been a lack of agreement on how many wine involvement groups exist $[10,12-14]$. Thus, revisiting the existing scales and 
testing which of the questions are valid and reliable and which are not in a wine consumption context, may be of benefit for future studies investigating consumers' level of product involvement with wine.

\subsection{Segmentation of Wine Consumers}

Typically, consumers' levels of involvement with wine have been classified into either high or low involvement [15]. Further studies segmented wine consumers based on the occasion, types (price/quality) of wines, types of consumer attitudes, consumers' consumption and demographic types [16] or wine knowledge and involvement [14]. It has been found that high and low-involvement consumers behave differently [17, 18]. High-involvement consumers like to maximise their expected satisfaction through an extensive choice process [4]. They are information seekers and they use this information during the decision-making process to make purchase decisions [17]. Thus, high-involvement consumers go through stages of 'awareness and comprehension' [19]. In contrast, low-involvement consumers are likely to simplify their product choice by using a small number of product cues such as price and label design [12]. However, there is increasing recognition of the existence of more than two wine consumer segments, including the medium-involvement segment and the new wine drinkers [3, 12-14]. As such, it remains unclear how many segments should be taken into consideration when dealing with wine consumers. This lack of agreement can be translated into confusion for the industry as it may mean marketers overlook or misinterpret the various consumer segments.

\section{Methodology}

This study consisted of a two-step methodology. First, an online questionnaire was used to screen and recruit participants $(n=44)$ based on their level of involvement with wine. Then, participants were split into four focus groups based on the level of product involvement identified through the questionnaire. The present study was conducted in Dunedin, in the South Island of New Zealand between November 2011 and June 2012. Dunedin is a University City, which is located in the South Island of New Zealand. Close to Dunedin (two hours by highway driving) is Central Otago, which is a renowned wine production region.

\section{Participants}

Participants were recruited through advertisements that were distributed to shopping areas, public places and by word-of-mouth. Socio-demographic information (e.g. gender, age, level of qualification, and income) and commercial background of each participant was collected. Table 1 contains the social-demographic details of participants. Ethics approval was obtained from the University of Otago's Ethics Committee (Reference number
$11 / 188)$.

Table 1. Socio-demographic details of participants

\begin{tabular}{|c|c|}
\hline Characteristics & Percentage $(n=44)$ \\
\hline \multicolumn{2}{|l|}{ Gender } \\
\hline Male & 50.0 \\
\hline Female & 50.0 \\
\hline \multicolumn{2}{|l|}{ Age } \\
\hline $18-24$ & 25.0 \\
\hline $25-29$ & 2.4 \\
\hline $30-34$ & 15.9 \\
\hline $35-39$ & 6.8 \\
\hline $40-44$ & 6.8 \\
\hline $45-49$ & 9.1 \\
\hline $50-54$ & 15.9 \\
\hline $55-59$ & 4.5 \\
\hline $60-65$ & 9.1 \\
\hline Over 65 & 4.5 \\
\hline \multicolumn{2}{|l|}{ Highest Level of Education } \\
\hline NCEA level 2 (or 6th form) & 6.8 \\
\hline NCEA level 3 (or 7th form) & 18.2 \\
\hline Polytechnic diploma & 2.3 \\
\hline Bachelor's degree & 20.5 \\
\hline University postgraduate diploma & 15.9 \\
\hline Masters or PhD degree & 29.5 \\
\hline Trade certificate & 2.3 \\
\hline Other & 4.5 \\
\hline \multicolumn{2}{|l|}{ Monthly Household Income } \\
\hline Less than $\$ 25,000$ & 27.4 \\
\hline$\$ 25,000-\$ 40,000$ & 13.6 \\
\hline$\$ 40,001-\$ 60,000$ & 9.1 \\
\hline$\$ 60,001-\$ 80,000$ & 13.6 \\
\hline$\$ 80,001-\$ 100,000$ & 15.9 \\
\hline$\$ 100,001-\$ 120,000$ & 6.8 \\
\hline$\$ 120,001-\$ 140,000$ & 4.5 \\
\hline$\$ 140,001-\$ 160,000$ & 6.8 \\
\hline More than $\$ 170,000$ & 2.3 \\
\hline
\end{tabular}

\subsection{The Online Questionnaire}

An online questionnaire measured participants' level of product involvement. Consumers' involvement with wine was measured using an adapted version of the Components of Involvement Scale (CP) [20]. Previous studies measured product involvement using a multi-item Likert scale [21]. Multi-item scales are typically preferred to single item scales because they have greater reliability and validity [22]. To establish the internal consistency of the scale, Cronbach's alpha was calculated for the survey responses $[3,23]$ as well as the Pearson product-moment correlation coefficient 
(PPMCC) between each possible pair of questions. Two questions out of nine were discarded due to insignificant correlations with the other seven. The ratings for each of the seven items (see Table 2) were summed and thus an involvement score was calculated for each respondent. To create high- and low-involvement groups, the respondents were split based on their scores at the median value $[3,10]$. Higher scores than the median corresponded with a high level of involvement.

\subsection{The Focus Group}

After completing the online questionnaire (based on their age and commercial background), and identifying those with professional knowledge, participants were placed into one of four focus groups. This was done to avoid more knowledgeable participants dominating the discussion and to encourage communication during the focus group session, as participants would feel more confident to express their opinions without seeming uninformed. Focus groups one $(n=12)$ and two $(n=10)$ consisted of randomly allocated participants from the rest of the respondents. Focus group three consisted of individuals who had a background in the wine profession $(n=11)$ such as commercial wine purchasers, retailers, distributors, and wine commentators. Focus group four consisted of those who were under the age of $28(n=11)$. Focus group responses were analysed thematically and participants' responses during the focus groups were compared to the different involvement groups and their characteristics identified in the literature (see Table 4 for various example used to classify the focus group participants into different involvement levels). The responses were then categorized into involvement groups through asking questions such as: Did they have professional or institutional experience? Were they information seeking (e.g., did they go to a speciality wine store to purchase their wine)? Did they react positively to higher prices (e.g., did they see a higher price as an indicator of quality)? These characteristics indicate a high level of involvement. On the other hand, did they frequently consume cheap wine or were they attracted by the colour of the label? These characteristics suggest a lower involvement level.

\section{Questionnaire Results}

The questions were shown to be internally consistent with Cronbach's alpha $=0.89$ [3]. This was also reflected in the Pearson's $r$ coefficient, which showed that the questions were all positively correlated (Pearson's $r>0$ for each pair of questions). These correlations were significant with $p<0.05$ and the strength of the relationships were in the desirable range of moderate $(0.3-0.6)$ or high $(>0.6)$, emboldened in Table 2 below, with the sole exception of the pairwise correlation between questions five and seven whose mutual correlation was low in strength $(<0.3)$ and had a p-value greater than the critical alpha of $0.05(p=0.058)$ as shown in Table 3.

Table 2. Questionnaire questions to measure participants' involvement with wine based on the Components of Involvement Scale (CP). Adapted from Lastovicka and Gardner [20, p. 239]

\begin{tabular}{cc}
\hline & Questionnaire Questions \\
\hline 1 & Wine is a topic that I could talk about for a long time. \\
2 & $\begin{array}{c}\text { I understand the different types of wine well enough to evaluate the } \\
\text { brands. }\end{array}$ \\
4 & Wine is subject that interests me. \\
5 & I have a preference for one or more styles of wine. \\
6 & Wine is a product that I have little interest in. * \\
7 & There are specific vineyards I regularly purchase wine from. \\
\hline
\end{tabular}

*Denotes items that are reverse scored.

\section{Focus Group Results}

From the focus group responses, participants were placed into one of five involvement groups, four of which were identified in the literature. Examples of typical quotations from participants used to classify them into their corresponding level of involvement are given in Table 4 . The participants were segmented as expert consumers (ECs, $n=$ 9), high- involvement consumers (HICs, $n=4$ ), medium-involvement consumers (MICs, $n=8$ ), low-involvement consumers (LICs, $n=20$ ) and new wine drinkers (NWDs, $n=3$ ). The expert consumer group had not before been considered as an involvement group, but as shown Table 3, it was easily distinguishable from the other groups, mainly because of the professional affiliations of its members. Further evidence for the distinctiveness of the ECs is given by the relationship between the survey scores and focus group-derived involvement groups. ECs generally have high survey scores, but their scores overlap with two out of four HICs, two out of eight MICs and one out of twenty LICs. HICs generally have higher scores than MICs and LICs. Overall, twenty-nine out of forty-four participants were allocated into a different involvement group after conducting both the questionnaire and focus group responses (see Table 3).

Table 3. Two-tailed Pearson's correlations between the different questionnaire (full questions are in Table 1) responses and sigma values indicating statistical significance $(n=44)$. "Q number indicates question number".

\begin{tabular}{llllllll}
\hline & & $(\mathrm{Q})$ & $(\mathrm{Q} 3)$ & $(\mathrm{Q} 4)$ & $(\mathrm{Q} 5)$ & $(\mathrm{Q})$ & $(\mathrm{Q} 7)$ \\
\hline (Q1) & PPMCC & $\mathbf{. 7 1 7}^{* *}$ & $\mathbf{. 6 5 4}^{* *}$ & $.580^{* *}$ & $.302^{*}$ & $\mathbf{. 6 1 2}^{* *}$ & $.392^{* *}$ \\
(Q2) & PPMCC & & $\mathbf{. 7 5 7}^{* *}$ & $\mathbf{. 6 4 3}^{* *}$ & $.517^{* *}$ & $\mathbf{. 7 1 9}^{* *}$ & $.486^{* *}$ \\
(Q3) & PPMCC & & & $\mathbf{. 6 2 7}^{* *}$ & $.497^{* *}$ & $\mathbf{. 8 3 9}^{* *}$ & $.474^{* *}$ \\
(Q4) & PPMCC & & & & $.489^{* *}$ & $\mathbf{. 6 4 5}^{* *}$ & $.490^{* *}$ \\
(Q5) & PPMCC & & & & & $.545^{* *}$ & .287 \\
(Q6) & PPMCC & & & & & & $.494^{* *}$ \\
\hline
\end{tabular}


These participants changed from high to medium involvement (8/31) or low-involvement (8/31), from high to expert involvement $(9 / 31)$, from high to New Wine Drinkers $(1 / 31)$ and two changed from low involvement to New Wine Drinkers (2/31). The remaining fifteen participants did not change their involvement level and most of these (10/15) were low-involvement consumer and were high-involvement
(4/15). All involvement groups frequently used awards for particular purposes. MICs, HICs as well as ECs were selective about which awards they used; for example, the "Cuisine award" (from a consumer magazine), was considered trustworthy. Table 5 shows the behaviour profiles of the different involvement segments around wine awards, which were identified using qualitative research methods.

Table 4. Examples of a typical quotation from different participants used for classification.

\begin{tabular}{|c|c|c|c|}
\hline $\begin{array}{l}\text { Examples of participants' quotes from different } \\
\text { focus groups }\end{array}$ & Supporting reference from the literature & $\begin{array}{l}\text { Questionnaire score } \\
\text { and level of } \\
\text { involvement }\end{array}$ & $\begin{array}{l}\text { Level of } \\
\text { involvement } \\
\text { according to the } \\
\text { focus group }\end{array}$ \\
\hline $\begin{array}{c}\text { "I am a wine writer. So I am also a consumer and } \\
\text { we have a cellar and I have tasted an awful lot of } \\
\text { wine." }\end{array}$ & $\begin{array}{c}\text { Has a longstanding experience with the product } \\
\text { category and have undergone a formal training } \\
\text { regime [24]. }\end{array}$ & $\begin{array}{l}\text { score }=52 \\
\text { HIC }\end{array}$ & EC \\
\hline $\begin{array}{c}\text { "If I really needed to choose a nice bottle of wine, I } \\
\text { would go down to [name of the wine specialty } \\
\text { store] and ask them." }\end{array}$ & $\begin{array}{l}\text { They will often need the confidence of the } \\
\text { retail assistant [14]. }\end{array}$ & $\begin{array}{l}\text { score }=36 \\
\text { HIC }\end{array}$ & MIC \\
\hline "I am a complete novice." & $\begin{array}{l}\text { Do not relate to wine as part of their lifestyle } \\
\qquad[25] .\end{array}$ & $\begin{array}{l}\text { score }=41 \\
\text { HIC }\end{array}$ & LIC \\
\hline $\begin{array}{c}\text { "Like festive days or Christmas, my family usually } \\
\text { has wine and I probably just have whatever they got } \\
\text { there... I don't have a specific liking towards } \\
\text { wine." }\end{array}$ & $\begin{array}{l}\text { Young and attracted by the behaviour of } \\
\text { parents or peers [14]. }\end{array}$ & $\begin{array}{l}\text { score }=36 \\
\text { LIC }\end{array}$ & NWD \\
\hline
\end{tabular}

Table 5. Behaviour profiles of the different involvement segments around wine awards.

Behaviour profiles around wine awards

ECs are wine consumers who have institutional experience with wine and/or have received training in this product category. This group is mainly influenced by wine writers and they purchase frequently in bulk via the internet, wineries, or wine speciality stores. However, they are attentive to 'trophy winners' (the highest wine award category) and try sometimes wine with a gold medal.

HICs are knowledgeable about wine and they appear not to be attracted by awards. They like to experiment and to try different types of wine and they are most likely to be influenced by the media, salespeople, friends and hospitality providers.

MICs are less knowledgeable than HICs and more knowledgeable than LICs. They are likely to use awards when choosing unfamiliar wine, principally as a means of quality control (e.g., when selecting wine as a gift). They often seek the advice from sales peoples in speciality wine stores and use well-known awards.

LICs are primarily price driven. A gold medal influences them when under time pressure and when the price of the wine is reduced. Purchase their wine in the supermarket and they pay attention to "fancy" labels.

NWDs are young wine consumers who are influenced by parents or peers, have not established preferences and often use price as the main determinant of their purchase. This group has no knowledge about wine awards. However, they sometimes use gold medals because they found them 'pretty and shiny'. 


\section{Discussion and Conclusions}

The change in involvement classification from high to medium or low indicates that marketers using involvement scales in the past may have targeted some wine products at the wrong market. Such problems indicate that wine specific scales should be formulated with careful consideration of the form of the questions. For example, if we asked two different consumers (one who really enjoys drinking wine and who has an extensive wine knowledge, and another consumer who only drinks wine to get drunk and who only likes to purchase cheap wine) to answer this question: "I have a strong interest in wine", both might answer, "strongly-agree". In this case, although both consumers have different behaviours (which would be unknown when conducting a questionnaire), they would gain the same score in the data analysis. This procedure would not indicate that the person who only drinks wine "for the effect of alcohol on the body" [26, p. 139], would, according to their behaviour, generally be classified in a low-involvement level. In another study participants were asked the fallowing question, "I own proper wine glasses" (e.g., Riedel or Spiegelau) [6, p. 469]. When asking this question, the participants' of the study may answer the question differently depending on their background. That is, it may be possible that they have received the wine glasses as a present and will, therefore, answer, "strongly-agree", although they do not drink wine. Therefore, it is likely that by only using the quantitative results, both consumers would be classified as high involvement. This will most likely lead to inaccurate results and could explain the lack of agreement in the literature. As this study highlights, ambiguities and discrepancies may have now crept in and so there is a need to reconsider how researchers and marketing practitioners utilize these scales to ensure that involvement levels more usefully reflect consumer knowledge segmentation and thus decision-making profiles. Overall, the segmentation of consumers (by their qualitative focus group responses) into five groups appears to have worked well due to the more detailed information contained therein.

The present study has some limitations. First, as with any qualitative study, the sample size was small $(n=44)$ and the results may lack generalizability. However, after conducting fur focus groups, saturation was achieved and no new salient information was obtained. A second limitation is that the present study did not follow up with participants on the issues observed regarding the meaning, and their understanding, of the questionnaire. It would have been valuable to explore this further with a different and larger focus group size to investigate if the interpretations made in the present study exhibit similarity. In future studies, wine marketers might consider constructing a scale specific to involvement, while being careful that the questions capture the desired characteristics of each segment. Such a specific scale has been formulated for food involvement [26, p. 139]. We propose a similar approach for measuring involvement. The authors were careful to capture behaviours specific to food and they developed the scale using participants to generate statements reflecting phases of food involvement. For example, [27] used the question: "When I eat out, I don't think or talk much about how the food tastes". This question could be adapted for wine involvement as it discriminates between those who drink for the taste from those who drink to get drunk.

\section{Acknowledgements}

We would like to thank the University of Otago, Applied Science Program, for awarding the Home Science/ Todhunter/Carpenter Scholarship to conduct this research.

\section{REFERENCES}

[1] Pellemans PA. The consumer decision-making process. European journal of Marketing. 1971;5(2):8-21.

[2] Solomon M. Consumer Behaviour: Buying, Having, and Being. Tenth ed. England: Pearson Education Limited; 2013.

[3] Zaichkowsky J. Measuring the involvement construct. Journal of Consumer Research. 1985;12(3):341-52.

[4] Laurent G, Kapferer J. Measuring consumer involvement profiles. Journal of Marketing Research (JMR). 1985;22(1).

[5] Mittal B, Lee M. A causal model of consumer involvement. Journal of Economic Psychology. 1989;10(3):363- 89.

[6] Bruwer J, Huang J. Wine product involvement and consumers' BYOB behaviour in the South Australian on-premise market. Asia Pacific journal of marketing and logistics. 2012;24(3):461-81.

[7] Lastovicka J. Questioning the Concept of Involvement Defined Product Classes. Advances in Consumer Research. 1979;6(1).

[8] Martin B, Marshall R. The interaction of message framing and felt involvement in the context of cell phone commercials. European Journal of marketing. 1997;33(1/2):206-18.

[9] Hollebeek L, Jaeger S, Brodie R, Balemi A. The influence of involvement on purchase intention for new world wine. Food Quality and Preference. 2007;18(8):1033- 49.

[10] Lockshin L, Jarvis W, d'Hauteville F, Perrouty J. Using simulations from discrete choice experiments to measure consumer sensitivity to brand, region, price, and awards in wine choice. Food Quality and Preference. 2006;17(34):166- 78.

[11] Quester P, Smart J. The influence of consumption situation and product involvement over consumers' use of product attribute. Journal of Consumer Marketing. 1998;15(3):22038 .

[12] Barber N, Ismail J, Dodd T. Purchase attributes of wine consumers with low involvement. Journal of Food Products Marketing. 2007;14(1):69-86. 
[13] Charters S, Pettigrew S. Product involvement and evaluation of wine quality. Qualitative Market Research: An International Journal. 2006;9(2):181- 93.

[14] Spawton T. Marketing planning for wine. European Journal of Marketing. 1991;25(3):6-48.

[15] Aurifeille J, Quester P, Lockshin L, Spawton T. Global vs international involvement-based segmentation: A cross-national exploratory study. International Marketing Review. 2002;19(4/5):369-86. PubMed PMID: 224343442. English.

[16] Gluckman R. A consumer approach to branded wines. European Journal of Marketing. 1990;24(4):27- 46.

[17] Barber N, Almanza B, Dodd T. Relationship of wine consumers' self confidence, product involvement, and packaging cues. Journal of Foodservice Business Research. 2008;11(1):45-64.

[18] Lockshin L, Hall J. Consumer purchasing behaviour for wine: what we know and where we are going: University of South Australia, Wine Marketing Research Group; 2003.

[19] Bruwer J, Buller C. Product involvement, brand loyalty, and country-of-origin brand preferences of Japanese wine consumers. Journal of Wine Research. 2013;24(1):38-58.

[20] Lastovicka J, Gardner D. "Components of Involvement". In: Maloney J, C, Silverman B, editors. Attitude Research Plays for High Stakes. Chicago: American Marketing Association 1979. p. 53- 73.

[21] Lastovicka J, Gardner D. Low involvement versus high involvement cognitive structures. Advances in consumer research. 1978;5(1):87-92.

[22] Sarstedt M, Wilczynski P. More for Less? A Comparison of Single-Item and Multi-Item Measures. Die Betriebswirtschaft: DBW. 2009;69(2):211-27.

[23] Verbeke W, Vackier I. Profile and effects of consumer involvement in fresh meat. Meat Science. 2004 5//:67(1):159-68.

[24] Schiefer J, Fischer C. The gap between wine expert ratings and consumer preferences International Journal of Wine Business Research. 2008;20(4):335- 51.

[25] Lockshin L, Quester P, Spawton A. Segmentation by involvement or nationality for global retailing: a cross-national comparative study of wine shopping behaviours. Journal of Wine Research. 2001;12(3):223- 36.

[26] Charters S. The contemporary wine consumer: The social and cultural context of a drink Wine \& Society: Elsevier Ltd.; 2006. p. 205-26.

[27] Bell R, Marshall DW. The construct of food involvement in behavioral research: scale development and validation 证. Appetite. 2003;40(3):235-44. 